\title{
O PREÂMBULO DA CONSTITUIÇÃO BRASILEIRA DE 1988 CONSAGRA A TEORIA AXIOLÓGICA DOS DIREITOS E GARANTIAS FUNDAMENTAIS?
}

\author{
Janaína Soares Noleto Castelo Branco \\ Mestra em Direito Público pela Universidade Federal do Ceará. \\ Professora de Direito Processual Civil da UFC. Procuradora Federal. \\ janainancb@yahoo.com.br
}

Sumário: 1) Caráter político dos preâmbulos nos primórdios do constitucionalismo moderno. 2) Natureza jurídica do preâmbulo. 3) A consagração da teoria axiológica dos direitos e garantias fundamentais pela Constituição Federal de 1988. Conclusões.

Resumo: O texto aborda o polêmico tema da natureza jurídica do preâmbulo constitucional. Analisa posições doutrinárias e jurisprudenciais a respeito. Também analisa seu papel dentro do sistema normativo como parâmetro hermenêutico e elemento de integração. Por fim, aborda a consagração da teoria axiológica dos direitos fundamentais pelo preâmbulo da Constituição Federal de 88.

Palavras-chave: Preâmbulo. Direitos Fundamentais.

\section{CARÁter POLÍTICO dOS PREÂMBULOS NOS PRIMÓRDIOS DO CONSTITUCIONALISMO MODERNO}

O constitucionalismo, fenômeno histórico-cultural da passagem do Antigo Regime para a Modernidade, surgiu, primordialmente, para privilegiar os interesses dos Estados burgueses, nos quais afloravam ideias como direitos individuais dos cidadãos, princípio da separação dos poderes e representação política e democrática.

O Estado burguês imprescindia de um instrumento para institucionalizar seus ideais e, então, romper definitivamente com o absolutismo monárquico.

Nos Estados Unidos, já no final do século XVIII, após a independência das 13 Colônias, surge a primeira constituição escrita e rígida da América e do mundo: a Constituição dos Estados Unidos da América de 1787.

O constitucionalismo francês veio envolto a um forte movimento sóciopolítico, em que se apregoavam ideais de liberdade, igualdade e fraternidade. Foi 
nesse contexto que, em 1791, logo após a Revolução Francesa, surgiu a primeira constituição escrita da França.

A ideia de supremacia constitucional é decorrência lógica do contexto em que nasceu o constitucionalismo. Era necessário que o "pacto fundador" se impusesse política e juridicamente. E nessa perspectiva define Canotilho a dupla função desse produto legislativo máximo: "garantia do existente e programa ou linha de direção para o futuro". iv Já no início do século XIX, o liberalismo, e juntamente com ele o constitucionalismo, que lhe serve de alicerce, difundem-se globalmente.

As primeiras constituições, no entanto, tinham feições marcadamente políticas. E era razoável que assim fosse, posto que foram produtos de revoluções que operaram a superação de um modelo de Estado - absolutista - por outro - liberal.

A Declaração de Direitos do Homem e dos Cidadãos, de 1789, é expressão dos ideais políticos da época. No entanto, naquela ocasião, não era vista como norma, ou seja, não possuía valor jurídico.

Também os preâmbulos, por muito tempo, não tiveram reconhecida a sua normatividade. Aliás, ainda atualmente há quem os tenha como preceitos não jurídicos, de cunho nitidamente político, como passaremos a demonstrar adiante.

Assevera Paulo Bonavides que, no período de maior efervescência liberal, em que até mesmo os textos constitucionais eram vistos apenas sob o prisma político, os preâmbulos "se assemelhavam primeiro a textos de literatura moral, religiosa ou filosófica, do que a verdadeiras leis portadoras de normas jurídicas vinculantes." ${ }_{\text {ii }}$

Esclareça-se de logo o que significa ter normatividade, juridicidade. Normativo é aquilo que possui eficácia vinculante. Tudo quanto está presente no texto constitucional é jurídico, é normativo. Já se encontra ultrapassada a visão de que apenas algumas normas constitucionais possuem normatividade, enquanto outras seriam apenas programas de ação, sem possibilidade de serem exigidas ${ }^{i i i}$. Reconhecer que determinado texto tem apenas valor político significa negar-lhe vinculação, não podendo o cidadão acionar o Estado para exigir sua aplicação. Significa, em última análise, que tem por função unicamente a de orientar os membros de poder em sua atuação política.

A noção de Estado de Direito foi alcançada em meados do século XIX, quando as constituições passaram a ser vistas também sob o aspecto jurídico. Aos poucos, também as declarações de direitos vêm tendo reconhecida sua juridicidade, vinculando os países que lhe são signatários.

Mas, se já se alcançou a percepção do sistema constitucional como um sistema jurídico, por que ainda se tergiversa acerca do caráter político ou jurídico dos preâmbulos constitucionais?

O grande dilema doutrinário é: O preâmbulo integra o texto constitucional? A resposta a esse questionamento soluciona qualquer controvérsia acerca da juridicidade do preâmbulo. Se é parte da Constituição, partilha de suas características e é norma. Do contrário, é simples apresentação do texto constitucional, 
impregnada de teor político, meramente político, e não vincula o legislador ordinário ou o aplicador da lei.

Após a superação da problemática exposta supra no decorrer deste estudo, persistem ainda outras questões: O preâmbulo da Constituição Brasileira de 1988 consagra a teoria axiológica dos direitos fundamentais? Em caso positivo, qual a utilidade de tal consagração?

\section{NATUREZa JURÍdicA do PREÂMBULO}

Gérson Marques de Lima, ao tratar da aplicação do bloco de constitucionalidade no Brasil, esclarece que o preâmbulo é um seu componente, ou seja, é parte da Constituição, donde concluir-se que "sua força normativo-vinculativa atinge o mesmo patamar do restante do referido bloco"vi.

Ora, se o preâmbulo compõe a Constituição Federal, é mister concluir que se trata de norma jurídica, posto que a parte compartilha da essência do todo. A Constituição é indubitavelmente um conjunto de normas jurídicas. Do contrário, faltar-lhe-ia a juridicidade, a vinculatividade, a utilidade. Ficamos com esta posição.

Parte da doutrina nacional entende, no entanto, que o preâmbulo não participa da constituição, não passando de um seu intróito.

Manoel Gonçalves Ferreira Filho afirma categoricamente que "o preâmbulo da Constituição não possui força obrigatória, destina-se simplesmente a indicar a intenção do constituinte. " "E prossegue salientando sua importância para o intérprete da carta constitucional. Deixa, assim, de reconhecer-lhe vinculatividade, força normativa.

O Supremo Tribunal Federal, nessa esteira, ao julgar ação direta de inconstitucionalidade em que se alegava a não reprodução obrigatória de parte do preâmbulo da Constituição Federal pelo constituinte do Estado do Acre, decidiu pela impossibilidade de declaração de inconstitucionalidade de ato normativo por ofensa ao preâmbulo. Em seu relatório, o então relator Ministro Carlos Velloso concluiu, lastreado em vasta doutrina, que o preâmbulo, não sendo norma jurídica, não possui relevância para o direito, nestes exatos termos:

O preâmbulo, ressai das lições transcritas, não se situa no âmbito do Direito, mas no domínio da política, refletindo posição ideológica do constituinte. É claro que uma constituição que consagra princípios democráticos, liberais, não poderia conter preâmbulo que proclamasse princípios diversos. Não contém o preâmbulo, portanto, relevância jurídica. ${ }^{\mathrm{vi}}$ (Grifamos).

Não apoiamos a posição da Suprema Corte. O preâmbulo é sim norma constitucional. Norma constitucional que consagra princípios repetidos no texto da Constituição, mas que nem por isso carece de relevância jurídica. O preâmbulo 
é norma componente do topo da pirâmide normativa de um ordenamento e forma, juntamente com os artigos da Constituição Federal, um todo normativo, segundo os princípios da supremacia e da unidade da Constituição.

Não se alegue que não é norma por não lhe anteceder o vocábulo "artigo" ou por não ser essencial à existência de uma Constituição, pois isto corresponderia a retirar a juridicidade de boa parte das normas contidas em uma constituição analítica, como é o caso da nossa atual constituição, posto que vários de seus dispositivos não constituiriam aquilo a que se denomina de constituição material ${ }^{\text {vii }}$, por serem dispensáveis à caracterização de uma carta política ${ }^{\text {viii. }}$.

Se é verdade que há cartas constitucionais sem preâmbulo, não é menos verdade que estando estes presentes não possuam força normativa. Se o legislador constituinte, ilimitado em seu mister de elaborar o diploma fundamental de determinada sociedade, opta por iniciar sua obra com a proclamação da fórmula política do Estado em criação e a consagração sintética dos valores supremos do povo, não há como deixar de reconhecer especial destaque de tal preceito para a ordem jurídica que se instala.

O preâmbulo é posto em votação tal quais os demais dispositivos constitucionais. É, portanto norma que prenuncia, de forma sintética, todo o arcabouço normativo que guiará o legislador e o aplicador da lei. É elemento de integração da Constituição e, por trazer consigo, embora de forma concisa, o espírito da constituição, tem como função primordial auxiliar o intérprete constitucional.

\section{A CONSAGRAÇÃO DA TEORIA AXIOLÓGICA DOS DIREITOS E GARANTIAS FUNDAMENTAIS PELA CONSTITUIÇÃo Federal de 1988}

O preâmbulo da Constituição Federal de 1988 consagra a teoria axiológica dos direitos e garantias fundamentais. É o que se infere da literalidade do texto:

\footnotetext{
Nós, representantes do povo brasileiro, reunidos em Assembléia Nacional Constituinte para instituir um Estado Democrático, destinado a assegurar o exercício dos direitos sociais e individuais, a liberdade, a segurança, o bemestar, o desenvolvimento, a igualdade e a justiça como valores supremos de uma sociedade fraterna, pluralista e sem preconceitos, fundada na harmonia social e comprometida, na ordem interna e internacional, com a solução pacífica das controvérsias, promulgamos, sob a proteção de Deus, a seguinte Constituição da República Federativa do Brasil.
}

Não há dúvidas, portanto, de que alberga a teoria axiológica dos direitos fundamentais. Ressalte-se a axiologia de que realmente se reveste o texto inicial da nossa Constituição, ao considerar os direitos fundamentais valores supremos. 
É fácil perceber que tudo quanto está proclamado no preâmbulo encontrase disseminado no restante do corpo constitucional, especialmente nos primeiros títulos (Título I - Dos Princípios Fundamentais e Título II - Dos Direitos e Garantias Fundamentais), com exceção de elementos não jurídicos do preâmbulo, como a invocação da proteção de Deus, que nada mais é que manifestação da religiosidade do povo brasileiro ${ }^{\text {ix }}$.

Qual o efeito prático da proclamação constitucional preambular da teoria axiológica dos direitos e garantias fundamentais, tendo em vista que esta se encontra disseminada no restante dos dispositivos da carta?

Cabe discorrer sobre a problemática. O preâmbulo, por ser a norma constitucional que apresenta as demais, prenunciando o seu conteúdo, é valiosíssimo instrumento de interpretação dos diversos dispositivos constitucionais, pois que contém a opção política do Estado, opção por um Estado Democrático e de Direito, ou seja, lastreado numa ordem constitucional e legal.

Willis Guerra Filho, após concluir ter o constituinte de 88 previsto, ainda no preâmbulo, o princípio do Estado Democrático de Direito, ou seja, a fórmula política, define-a como "elemento caracterizador da Constituição, principal vetor de orientação para a interpretação de suas normas, e, através delas, de todo o ordenamento jurídico"x. Portanto, serve de guia do legislador e do aplicador da lei.

Sendo norma que contém o que há de mais essencial no texto constitucional, é indubitável a importância da consagração da teoria axiológica dos direitos e garantias fundamentais pelo preâmbulo. Vincula não somente o intérprete, como também o legislador e o aplicador da lei.

\section{Conclusões}

O preâmbulo possui a natureza jurídica de norma, mas não uma norma qualquer, e sim uma norma que ocupa o ápice do ordenamento, posto que integrante da carta constitucional. Portanto, além de ter normatividade, o preâmbulo possui função de limitar a atividade legislativa, servindo-lhe de parâmetro. Na aplicação da lei, auxilia a interpretação da norma, bem como lhe serve de elemento de integração.

A doutrina não é majoritária em considerar normativa a natureza do preâmbulo. O Supremo Tribunal Federal entende que se trata apenas de preceito de relevância exclusivamente política.

O preâmbulo da Constituição Federal de 1988 consagra a teoria axiológica dos direitos fundamentais. Ocorre que os direitos fundamentais a que alude estão reproduzidos nos demais dispositivos constitucionais, especialmente no artigo $5^{\circ}$, o que acaba por amenizar a importância da discussão acerca da consagração de tais direitos naquela parte introdutória e sintética da carta constitucional. No entanto, tendo em vista o princípio da unidade axiológica da Constituição, e sendo 
o preâmbulo, como não poderia deixar de ser, um resumo dos valores contidos na Carta, é mister reconhecer que o preâmbulo é necessariamente consagrador da teoria axiológica dos direitos fundamentais, tendo, nesse aspecto, a mesma força vinculante, normativa, dos demais dispositivos constitucionais que consagram de forma mais detalhada tais direitos.

Ressaltamos, por fim, que há no preâmbulo mais que uma opção política ou uma norma jurídica. Há elementos culturais, como, por exemplo, aspectos da religiosidade do povo. Tais aspectos não são vinculantes porque despidos de juridicidade.

Possuindo, pois, o preâmbulo, como bem demonstramos, normatividade, tudo o que nele se contém de jurídico vincula o criador e o aplicador da lei.

\section{REFERÊNCIAS}

BONAVIDES, Paulo. Curso de Direito Constitucional. 6 ed., rev., atual. e ampl., São Paulo: Malheiros, 1996.

BUENO NETO, Francisco. Curso Acadêmico de Direito Constitucional. 2 ed., São Paulo: Editora de Direito, 1999.

CANOTILHO, J. J. Gomes. Constituição dirigente e vinculação do legislador. Coimbra: Coimbra Editora, 1994.

FERREIRA FILHO, Manoel Gonçalves. Comentários à Constituição Brasileira de 1988. Vol. 1. São Paulo: Saraiva, 1997.

GUERRA FILHO, Willis Santiago. Processo Constitucional e Direitos Fundamentais. 2 ed. rev. e ampl., São Paulo: Celso Bastos, 2001.

LIMA, Gérson Marques de. Bloco de constitucionalidade: os sistemas francês e espanhol. In Revista Opinião Jurídica. Ano II - n. 3 - 2004.1.

MARÇAL, Patrícia Fontes. Estudo Comparado do Preâmbulo da Constituição

Federal do Brasil. Rio de Janeiro: Forense, 2001.

THE PREAMBLE OF THE BRAZILIAN CONSTITUTION AND THE AXIOLOGICAL THEORY OF FUNDAMENTAL (HUMAN) RIGHTS

Abstract: This paper aims to investigate the normative force of preambles. It analyses if the preamble of the Brazilian Constitution contains the axiological theory of fundamental (human) rights.

Keywords: Preamble. Fundamental (Human) rights. 
i CANOTILHO, J. J. Gomes. Constituição dirigente e vinculação do legislador. Coimbra: Coimbra Editora, 1994. p. 151.

ii BONAVIDES, Paulo. Curso de Direito Constitucional. 6 ed., rev., atual. e ampl., São Paulo: Malheiros, 1996, p. 202.

iii A esse respeito, destacamos a posição de Rui Barbosa: "Não há, numa Constituição, cláusulas a que se deva atribuir meramente o valor moral de conselhos, avisos ou lições. Todas têm a força imperativa de regras, ditadas pela soberania nacional ou popular aos seus órgãos.” BARBOSA, Rui. Comentários à Constituição Federal Brasileira, II, São Paulo, 1933, p. 489, apud BONAVIDES, Paulo. Curso de Direito Constitucional. 6 ed., rev., atual. e ampl., São Paulo, Malheiros, 1996, p. 211.

iv LIMA, Gérson Marques de. Bloco de constitucionalidade: os sistemas francês e espanhol. In Revista Opinião Jurídica. Ano II - n. 3 - 2004.1, p. 106.

v FERREIRA FILHO, Manoel Gonçalves. Comentários à Constituição Brasileira de 1988. Vol. 1. São Paulo: Saraiva, 1997, p. 15. No mesmo sentido, Patrícia Fontes Marçal, ao afirmar que "o Preãmbulo não se reveste de caráter normativo e sua função é servir de instrumento à interpretação dos dispositivos inseridos na Carta Política. Nessa condições, não é lícito interpretar qualquer norma constitucional em desacordo com o preâmbulo". (MARÇAL, Patrícia Fontes. Estudo Comparado do Preâmbulo da Constituição Federal do Brasil. Rio de Janeiro: Forense, 2001, p. 4). No nosso entender, tal assertiva contém contradição, na medida em que se, segundo a autora, o preâmbulo não é norma jurídica, não possui força vinculante. Assim sendo, nada impediria o intérprete da Constituição de contrariar o texto preambular no seu mister hermenêutico.

vi ADIN n. 2.076-5 ACRE. Relator Ministro Carlos Velloso. Julgamento ocorrido em 15/08/2002. p. 226.

vii Segundo Paulo Bonavides, "Do ponto de vista material, a Constituição é o conjunto de normas pertinentes à organização do poder, à distribuição da competência, ao exercício da autoridade, à forma de governo, aos direitos da pessoa humana, tanto individuais como sociais. Tudo quanto for, enfim, conteúdo básico referente à composição e ao funcionamento da ordem política exprime o aspecto material da Constituição... As constiuições não raro inserem matérias de aparência constitucional. Assim se designa exclusivamente por haver sido introduzida na Constituição, enxertada no seu corpo normativo e não porque se refira aos elementos básicos ou institucionais da organização política." (BONAVIDES, Paulo. Curso de Direito Constitucional. 6 ed., São Paulo: Malheiros, 1996, pp. 63-64).

viii Ressalte-se que, apesar de não ser essencial à caracterização de uma carta constitucional, o preâmbulo esteve presente em todas as Constituições brasileiras, com exceção da Carta da República de 1937.

ix Acerca da invocação do nome de Deus pelo Constituinte de 88, lembra Francisco Bruno Neto que "é uma praxe constitucional brasileira. Fizeram-na as Constituições de 1824 e 1934. Não fez a de 1891, mas apenas porque estavam os constituintes republicanos preocupados em separar o Estado da Religião e assim acharam que a inserção do nome de Deus na Constituição viria concorrer para nova confusão." (BUENO NETO, Francisco. Curso Acadêmico de Direito Constitucional. 2 ed., São Paulo: Editora de Direito, 1999, p. 353-354). Ademais, ressalte-se que a maioria das constituições da América Latina invocam a proteção de Deus, diferentemente das constituições européias, por exemplo, o que reforça o argumento de que se trata de aspecto cultural, não jurídico, presente nos preâmbulos desses países.

x GUERRA FILHO, Willis Santiago. Processo Constitucional e Direitos Fundamentais. 2 ed. rev. e ampl., São Paulo: Celso Bastos, 2001. 